\title{
Notes on the vocalizations of of Varzea Thrush (Turdus sanchezorum) and Hauxwell's Thrush (Turdus hauxwelli)
}

Peter Boesman

In the following we briefly analyze and compare voice of Varzea Thrush (Turdus sanchezorum) and Hauxwell's Thrush (Turdus hauxwelli). We also try to quantify the extent of any vocal differences using the criteria proposed by Tobias et al. (2010), as a support for taxonomic review. We have made use of sound recordings available on-line from Xeno Canto (XC).

Varzea Thrush T. sanchezorum has only recently been described (O'Neill et al. 2011). The trigger which led to the discovery of this cryptic species was the 'mewing call' (similar to $T$. nudigenis), which is unlike any other Turdus thrush in the Amazon:

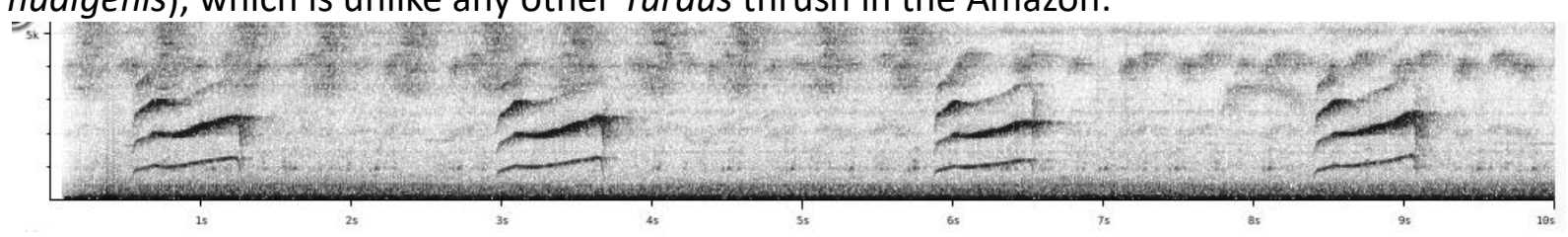

Song was not analyzed in depth in the paper describing this species, as not many recordings were available, which to date is still the case. Nevertheless, as noted in the paper, song is typically about 3-4s long, consisting of less than 10 rich fluty whistles, unlike the often nearcontinuous 'caroling' of e.g. Hauxwell's Thrush T. hauxwelli.

Some examples of song:

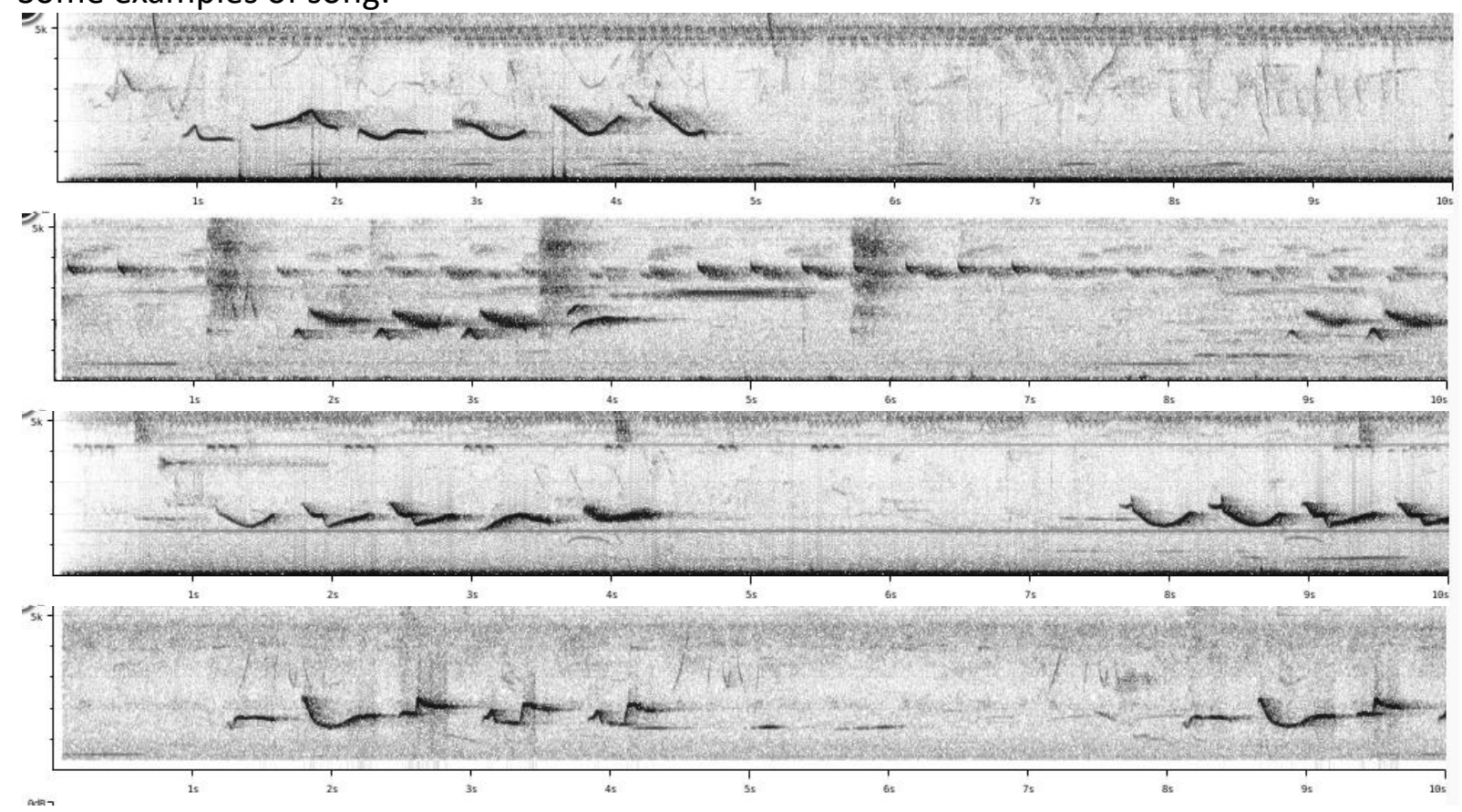




\section{HANDBOOK OF THE

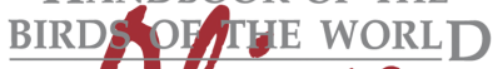 \\ Aluve}

\section{ORNITHOLOGICAL NOTES}

To be compared with song of hauxwelli:

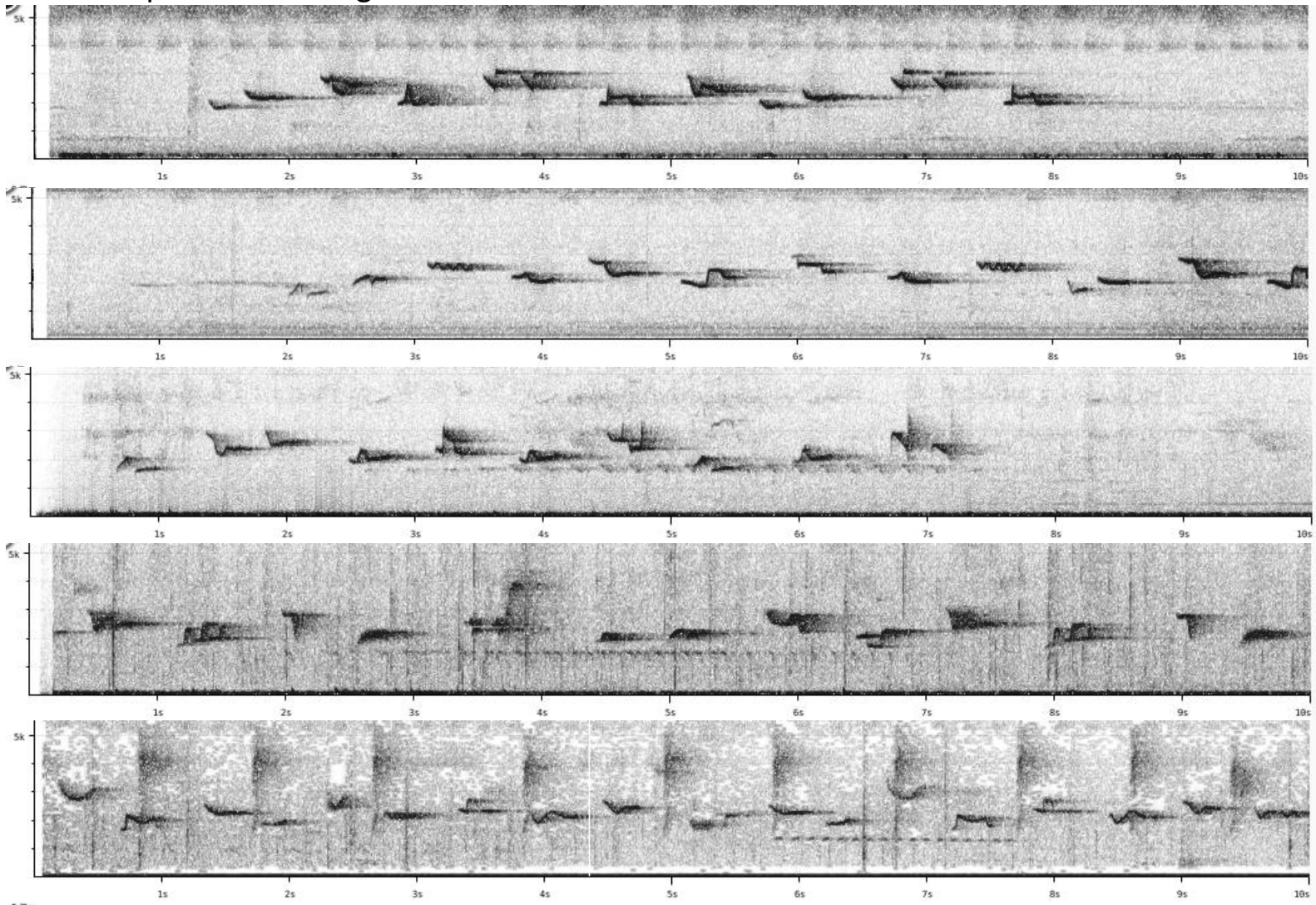

T. sanchezorum has typically a shorter song phrase (although some overlap, score 2 ) with less notes (score 2), while mewing call is diagnostic (nothing similar known for hauxwelli, based on e.g. much longer note length score 2-3). When applying Tobias criteria, this would lead to a total vocal score of about 4-5.

Given that the 'mewing call' is known from members of the T. nudigenis complex, it may actually make more sense to compare sanchezorum with these taxa.

Some examples of voice (song and call):

\section{T. nudigenis}

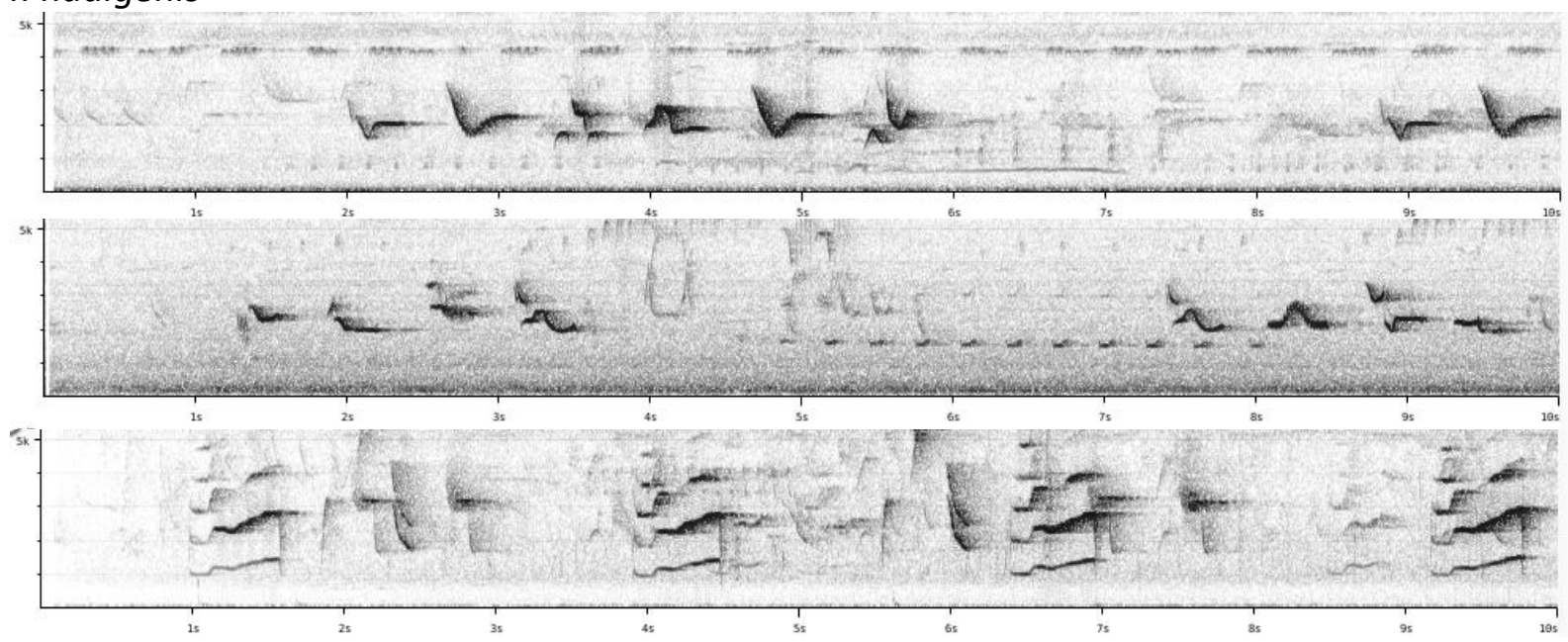



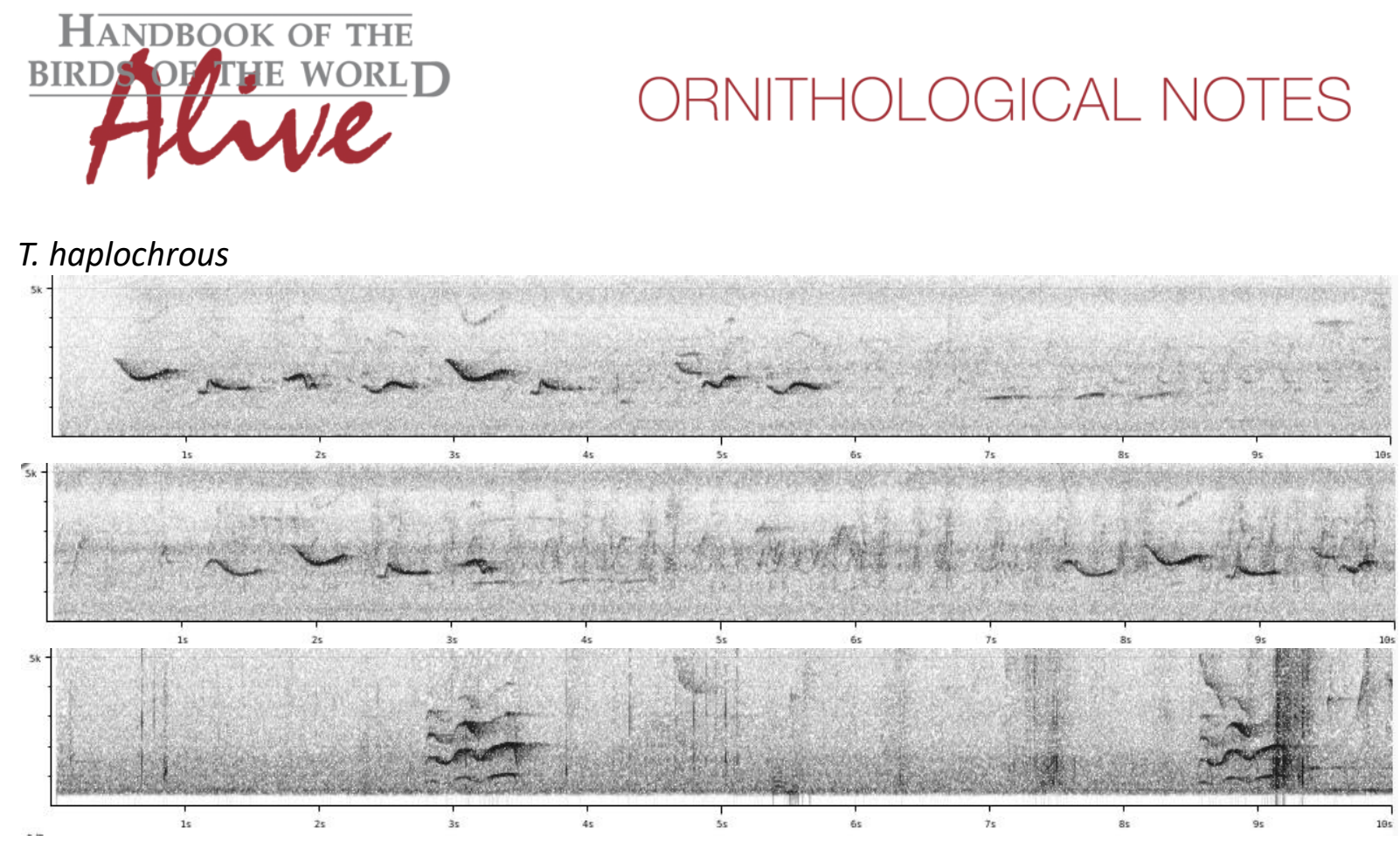

It is clear from the above examples that length of song phrase with number of notes, and a mewing call are nolonger distinguishing features of Varzea Thrush versus Spectacled and Unicolored Thrush.

A larger set of recordings would clearly be needed to find out if there are consistent vocal differences between these three species!

This note was finalized on 19th April 2016, using sound recordings available on-line at that moment. We would like to thank in particular the sound recordists who placed their recordings on XC for the species treated here.

\section{References}

O'Neill, J.P., Lane, D.F. \& Naka, L.N. (2011). A cryptic new species of thrush (Turdidae: Turdus) from western Amazonia. Condor 113(4): 869-880.

Tobias, J.A., Seddon, N., Spottiswoode, C.N., Pilgrim, J.D., Fishpool, L.D.C. \& Collar, N.J. (2010). Quantitative criteria for species delimitation. Ibis 152(4): 724-746.

\section{Recommended citation}

Boesman, P. (2016). Notes on the vocalizations of Varzea Thrush (Turdus sanchezorum) and Hauxwell's Thrush (Turdus hauxwelli). HBW Alive Ornithological Note 306. In: Handbook of the Birds of the World Alive. Lynx Edicions, Barcelona. (retrieved from http://www.hbw.com/node/1251762 on 14 October 2016). 